\title{
Energy balance of pregnant diabetic rats
}

\author{
Ruth Yamada, Mauro A. Griggio and Jacqueline Luz* \\ Federal University of São Paulo - São Paulo Medical School (UNIFESP) Department of Physiology, São Paulo, Brazil
}

(Received 31 January 2001 - Revised 6 November 2001 - Accepted 28 November 2001)

\begin{abstract}
Pregnancy and diabetes lead to metabolic alterations in the energy balance that may not be completely independent. The objective of the present study was to look at the alterations induced by type 1 diabetes mellitus on the energy balance of pregnant rats and the offspring. Diabetes was induced by streptozotocin injection $15 \mathrm{~d}$ before the starting of pregnancy. The rats had their energy balance variables followed for $21 \mathrm{~d}$. Protein, fat and energy content of dams was determined from samples of the carcasses. Pregnancy led to increased energy intake, energy gain and energy expenditure as well as higher gross food efficiency than nonpregnant counterparts. Diabetes increased metabolizable energy intake but not the energy gain of the animals: they had very high energy expenditure, so that diabetes blocked the improvement in gross food efficiency shown during pregnancy. Offspring from diabetic dams were born with lower body weight. Pregnant animals did not present the usual energy storage as seen by lower energy gain of diabetic dams as well as by the lower fat content in the carcasses of pregnant diabetic rats. It is concluded that diabetes impairs the energy variables usually enhanced by pregnancy alone.
\end{abstract}

Energy balance: Diabetes mellitus: Pregnancy: Energy expenditure

The regulation of energy balance involves the control of food intake and energy expenditure. During pregnancy, most animals increase their food intake (Chaves \& Herrera, 1980; Luz \& Griggio, 1990; Murphy \& Abrams, 1993) as well as the gross food efficiency (Naismith \& Brookes, 1983; Luz \& Griggio, 1990). Part of the extra energy ingested is used to form the uterine contents and for uterus growth (Rosso, 1975; Hay, 1991; Luz \& Griggio, 1992), and part is spent as heat as a consequence of the increased energy expenditure (Richard \& Trayhurn 1985; Lux \& Griggio, 1990). Furthermore, the major part of the extra intake is stored as fat to be used later during the lactation period when the energy demand is very high due to milk production (Andrews et al. 1986; Forsum et al. 1988; Trayhurn, 1989).

Diabetes mellitus (DM) is a chronic disorder of metabolism caused by an absolute or relative lack of insulin. Since insulin is the major storage hormone, minimal insulin deficiency results in diminished ability to increase the reservoir of body fuels. Major insulin deficiencies cause not only a decreased fuel accumulation in the fed state, but also an excessive mobilization of endogenous metabolic fuels in the fasting condition, leading to an elevated free fatty acid concentration, hyperglycaemia and hyperaminoacidaemia (Felig \& Bergman, 1995).
Increased energy expenditure is a characteristic of DM (Nair et al. 1984; Molnár et al. 1989) that usually leads the subjects to a compensatory state of hyperphagia. Higher costs of protein synthesis (Nair et al. 1984; Charlton and Nair, 1998a) and gluconeogenesis (Nair et al. 1984), as well as increased thermogenic response to adrenaline (Shamoon et al. 1980; Müller et al. 1989) have been associated with the increase in energy expenditure during the diabetic state.

The catabolic state of poorly controlled type 1 DM has largely been attributed to insulin deficiency. Because the increase in protein breakdown is greater than the increase in protein synthesis, insulin deprivation results in a net release of amino acids in skeletal muscle (Charlton \& Nair, 1998a), which suggests that insulin exerts an anticatabolic effect in type 1 DM mainly through the inhibition of muscle protein breakdown.

Hyperglucagonaemia coexists with insulin deficiency or insulin resistance as occurs in many catabolic conditions. It has been shown that hyperglucagonaemia during insulin deficiency results in an increase in energy expenditure (Charlton \& Nair, 1998b; Nair, 1987) and accelerated proteolysis (Nair et al. 1987).

Since both pregnancy and DM modify the energy balance, the purpose of the present study was to look at the

Abbreviation: DM, diabetes mellitus.

*Corresponding author: Dr Jacqueline Luz, fax +55 115575 9165, email jluz@ecb.epm.br 
alterations in the energy balance when pregnancy and DM are present and the repercussions on the offspring.

\section{Material and methods}

Fifty-three 3-month-old female Wistar EPM-1 rats with an initial body weight of 192.60 (SEM 1.74) $\mathrm{g}$ were used. The animal house was maintained at $23 \pm 2^{\circ} \mathrm{C}$ on a $12 \mathrm{~h}$ lightdark cycle. During the experimental period, half of the rats were kept non-diabetic and the other half were diabetic. For each state, non-diabetic or diabetic, two groups were studied: non-pregnant and pregnant rats, giving four experimental groups as follows: non-pregnant-non-diabetic ( $n$ 14), pregnant-non-diabetic ( $n$ 13), non-pregnant-diabetic ( $n$ 12) and pregnant-diabetic ( $n$ 14).

DM was induced by a single intraperitoneal dose of streptozotocin (Sigma, St. Louis, MO, USA) (60 mg/kg) (Geiger et al. 1992; Anderson et al. 1993) diluted in a citrate buffer solution $(0.2 \mathrm{M}, \mathrm{pH} 4.5)$ (Woongsurawat \& Armbrecht, 1991; Grishan, 1993). Non-diabetic animals were injected with citrate buffer solution in a equivalent volume. In the first $48 \mathrm{~h}$ after the streptozotocin administration, the animals were allowed to choose between two glucose solutions (25 and $50 \mathrm{~g} / \mathrm{l}$ ) in order to compensate for hypoglycaemia. After this period, all animals received water and food ad libitum. Seventy-two hours after the streptozotocin administration, one drop of blood was taken from the tail of the awake animals to determine the extent of glycaemia by a blood glucose meter (Advantage; Roche Diagnostics, São Paulo, SP, Brazil). The animals were considered diabetic only when the glycaemia was $2.50 \mathrm{mg} / \mathrm{ml}$ or higher and at this time they started receiving 1 IU Neutral Protamine Hagendorn (NPH) insulin/d subcutaneously at 17.00 hours (Biobrás, Montes Claros, Brazil) until the last day of the experiment. Control animals received daily injections of saline of the same volume. Fifteen days after streptozotocin administration, one male rat was introduced into a cage with four females and kept there overnight. The presence of spermatozoa in vaginal smears taken in the next morning indicated that mating had taken place and that day was considered the first day of pregnancy.

Pregnant and non-pregnant rats were housed in individual metabolic cages for $21 \mathrm{~d}$ (pregnancy period). At the end of experimental period $(21 \mathrm{~d})$, the animals were anaesthetized with sodium thiopental $(60 \mathrm{mg} / \mathrm{kg})$ and the abdominal cavity was opened. Samples of blood were taken into a tube with heparin by an aortic pricking and the uterine contents (offspring and placentas) were extracted and separated. The uterus and ovaries were separated and weighed. The gut was removed, emptied and put back into the carcass. The carcass was weighed (wet weight) and homogenized in a blender with an equal volume of water. Two samples of $2 \mathrm{~g}$ each were collected from the homogenized carcass to determine the fat and protein content. Offspring and placentas from each dam were separated and the number and weight were recorded. Just after the killing by decapitation, the blood of all pups was pooled together into tubes with heparin and their carcasses were weighed (wet weight). Placentas and the offspring carcasses were separately homogenized.
The carcasses of non-pregnant animals were processed in the same way as the pregnant ones. The homogenized material was dried to constant weight in an oven at $60^{\circ} \mathrm{C}$ (dry weight), and the resulting powder was rehomogenized before a sample was burnt in an adiabatic calorimeter (IKA C-400; Janke and Kunkel, GmbH \& Co., Breicgan, Germany). During the whole experimental period, faeces and urine were collected daily for energy content determination. Food intake was recorded daily and samples of pellets were frequently analysed in the calorimeter. Energy intake was calculated by multiplying the amount ingested (g) by the energy content of the diet. Absorbed energy was calculated as energy intake minus energy in the faeces. Metabolizable energy intake was considered as absorbed energy minus energy in the urine.

Body-energy gain was determined from a baseline group of sixty-five control and thirty-six diabetic rats killed on day 0 for each state studied (non-diabetic and diabetic). A regression of body weight $v$. body energy was calculated. The initial body energy of experimental animals was calculated from their body weight utilizing the regression equation calculated earlier. Body-energy gain corresponded to the energy in the carcasses minus the initial body energy. Energy expenditure over the $21 \mathrm{~d}$ experimental period was calculated as metabolizable energy intake minus body-energy gain. Gross food efficiency was calculated as energy gain divided by metabolizable energy intake and expressed as a percentage. To calculate energy expenditure and gross food efficiency the energy of offspring, placentas and uterus were added to maternal body-energy gain.

The percentage of water in the carcass was calculated by the difference between wet and dry weight and expressed as a percentage. Fat and protein content in the carcass was measured in the fresh samples of homogenized carcasses by chloroform-methanol (Folch et al. 1957) and Lowry (Leshner \& Litwin, 1972) methods respectively. Glycaemia in dams and pups was measured by an enzymatic colorimetric method (Glucose E KIT-CELM, São Paulo, SP, Brazil).

Statistical analysis was performed by two-way ANOVA. When significant, the Newman-Keuls test was applied to detect which means were different from each other. Glycaemia and variables at birth of offspring from non-pregnant and pregnant rats at different states (diabetic and non-diabetic) were analysed by $t$ test. The significance level to reject the null hypothesis was always set at 0.05 (Hirsch \& Riegelman, 1992).

All the procedures and methods with the animals were examined and approved by the ethics committee of the Federal University of São Paulo (UNIFESP-EPM).

\section{Results}

Table 1 shows that pregnant rats always had a higher body-weight gain (total and net) than the corresponding non-pregnant ones $(P<0 \cdot 05)$. DM led to a decrease in body-weight gain (total and net) of pregnant animals.

Table 2 shows the variables of energy balance as well as gross food efficiency and percentage of absorbed energy values. Pregnancy and DM let to an increase in metabolizable 
Table 1. Body-weight gain of non-pregnant and pregnant rats in different states (diabetic and non-diabetic) ${ }^{*} \dagger$

(Mean values with their standard errors)

\begin{tabular}{|c|c|c|c|c|c|c|c|c|c|}
\hline \multirow{4}{*}{ State... } & \multicolumn{9}{|c|}{ Body weight (g) } \\
\hline & & & & \multicolumn{6}{|c|}{ Pregnant } \\
\hline & \multicolumn{3}{|c|}{ Non-pregnant } & \multicolumn{3}{|c|}{ Total } & \multicolumn{3}{|c|}{ Net } \\
\hline & $n$ & Mean & SEM & $n$ & Mean & SEM & $n$ & Mean & SEM \\
\hline Non-diabetic & 14 & $17 \cdot 0^{\mathrm{a}}$ & $2 \cdot 6$ & 13 & $116 \cdot 6^{\mathrm{b}}$ & $5 \cdot 3$ & 13 & $54 \cdot 1^{d}$ & $2 \cdot 4$ \\
\hline Diabetic & 12 & $12 \cdot 8^{\mathrm{a}}$ & 3.5 & 14 & $94.79^{c}$ & 4.6 & 14 & $45 \cdot 0^{\mathrm{e}}$ & $3 \cdot 0$ \\
\hline
\end{tabular}

a,b,c,d,e Mean values with unlike superscript letters were significantly different $(P<0.05)$.

${ }^{*}$ For details of diets and procedures, see p. 510.

†Net body-weight gain corresponds to the total weight gain of the pregnant rats minus the weight of the conceptuses.

energy intake $(P<0 \cdot 05)$. Pregnant diabetic animals showed a significant reduction $(P<0 \cdot 05)$ in body-energy gain. The pregnant non-diabetic rats showed higher body-energy gain than the non-pregnant ones $(P<0 \cdot 05)$. The energy expenditure was significantly increased by pregnancy as well as DM $(P<0.05)$. As expected, the pregnant non-diabetic rats showed higher gross food efficiency $(P<0.05)$ than the respective non-pregnant ones, and decreased gross food efficiency $(P<0.05)$ was observed in pregnant diabetic animals. No significant differences $(P>0.05)$ for percentage of absorbed energy were detected.

The variables of body composition and glycaemia are shown in Table 3. Pregnancy did not affect $(P>0.05)$ these variables in both states (diabetic and non-diabetic), except that pregnant non-diabetic animals had higher protein content than non-pregnant ones. DM led to a decrease in fat $(P<0 \cdot 05)$, but not in water content $(P>0 \cdot 05)$. Obviously glycaemia was increased in diabetic rats $(P<0.05)$.
Table 4 shows the variables of the uterus from nonpregnant and pregnant animals. Uterus weight and energy content were significantly higher $(P<0 \cdot 05)$ for pregnant rats when compared with the respective non-pregnant animals. DM led to a reduction in uterus weight in both non-pregnant and pregnant animals $(P<0.05)$. Uterus energy content was not altered by DM $(P>0.05)$.

Table 5 shows the variables of urine from non-pregnant and pregnant animals. Pregnancy did not lead to significant differences $(P>0.05)$ in urinary volume, but increased $(P<0.05)$ urinary energy in non-diabetic rats. DM increased urinary volume and energy in both pregnant and non-pregnant animals $(P<0 \cdot 05)$.

The number, weight, energy content and glycaemia of the offspring are shown in Table 6. All values represent the average of pooled conceptuses. Maternal DM did not affect the number of pups or the placentas $(P>0 \cdot 05)$. The offspring energy content was also not affected by maternal

Table 2. Variables of energy balance, gross food efficiency and absorbed energy in non-pregnant and pregnant rats in different states (diabetic and non-diabetic)*

(Mean values with their standard errors)

\begin{tabular}{|c|c|c|c|c|c|c|}
\hline \multirow[t]{2}{*}{ State... } & \multicolumn{3}{|c|}{ Non-pregnant } & \multicolumn{3}{|c|}{ Pregnant } \\
\hline & $n$ & Mean & SEM & $n$ & Mean & SEM \\
\hline \multicolumn{7}{|c|}{ Metabolizable energy intake $(\mathrm{kJ} / 21 \mathrm{~d})$} \\
\hline Non-diabetic & 14 & $4209 \cdot 1^{a}$ & $210 \cdot 4$ & 13 & $5685 \cdot 6^{c}$ & $176 \cdot 3$ \\
\hline Diabetic & 12 & $5375 \cdot 6^{\mathrm{bc}}$ & $236 \cdot 6$ & 14 & $6374 \cdot 6^{\mathrm{d}}$ & 234.3 \\
\hline \multicolumn{7}{|c|}{ Energy gain $(\mathrm{kJ} / 21 \mathrm{~d})$} \\
\hline Non-diabetic & 14 & $214 \cdot 2^{\mathrm{a}}$ & $59 \cdot 8$ & 13 & $765 \cdot 6^{\mathrm{c}}$ & $105 \cdot 4$ \\
\hline Diabetic & 12 & $-10 \cdot 5^{a b}$ & $62 \cdot 6$ & 14 & $119 \cdot 6^{\mathrm{b}}$ & $65 \cdot 3$ \\
\hline \multicolumn{7}{|c|}{ Energy expenditure $(\mathrm{kJ} / 21 \mathrm{~d}) \dagger$} \\
\hline Non-diabetic & 14 & $3994.8^{a}$ & $198 \cdot 0$ & 13 & $4920 \cdot 2^{b}$ & $176 \cdot 0$ \\
\hline Diabetic & 12 & $5386 \cdot 1^{\mathrm{b}}$ & $269 \cdot 0$ & 14 & $6255 \cdot 5^{\mathrm{c}}$ & 263.7 \\
\hline \multicolumn{7}{|c|}{ Gross food efficiency (\%) } \\
\hline Non-diabetic & 14 & $4 \cdot 96^{a}$ & 1.33 & 13 & $13 \cdot 36^{b}$ & 1.69 \\
\hline Diabetic & 12 & $1.91^{\mathrm{a}}$ & 1.00 & 14 & $2 \cdot 11^{\mathrm{a}}$ & 1.11 \\
\hline \multicolumn{7}{|c|}{ Absorbed energy (\%) } \\
\hline Non-diabetic & 14 & $74 \cdot 27^{\mathrm{a}}$ & 0.93 & 13 & $74.89^{a}$ & 0.42 \\
\hline Diabetic & 12 & $73 \cdot 63^{\mathrm{a}}$ & 0.81 & 14 & $74 \cdot 32^{\mathrm{a}}$ & 1.26 \\
\hline
\end{tabular}

a,b,c,d Mean values with unlike superscript letters were significantly different: $P<0.05$.

${ }^{*}$ For details of diets and procedures, see p. 510.

† To calculate energy expenditure, the energy content of fetuses and placentas were added to maternal energy gain. 
Table 3. Variables of body composition (fat, protein and water in the carcass) and glycaemia of non-pregnant and pregnant rats in different states (diabetic and non-diabetic)*

(Mean values with their standard errors)

\begin{tabular}{|c|c|c|c|c|c|c|}
\hline \multirow[t]{2}{*}{ State... } & \multicolumn{3}{|c|}{ Non-pregnant } & \multicolumn{3}{|c|}{ Pregnant } \\
\hline & $n$ & Mean & SEM & $n$ & Mean & SEM \\
\hline \multicolumn{7}{|c|}{ Protein content $(\mathrm{g} / \mathrm{kg})$} \\
\hline Non-diabetic & 14 & $254 \cdot 35^{\mathrm{a}}$ & 11.45 & 13 & $288 \cdot 28^{b}$ & $12 \cdot 30$ \\
\hline Diabetic & 12 & $300 \cdot 38^{b}$ & $7 \cdot 16$ & 14 & $291 \cdot 01^{b}$ & 9.66 \\
\hline \multicolumn{7}{|c|}{ Fat content $(\mathrm{g} / \mathrm{kg})$} \\
\hline Non-diabetic & 14 & $126 \cdot 01^{a}$ & 7.89 & 13 & $137 \cdot 28^{a}$ & $10 \cdot 72$ \\
\hline Diabetic & 12 & $75 \cdot 15^{\mathrm{b}}$ & 5.43 & 14 & $84 \cdot 81^{\mathrm{b}}$ & $6 \cdot 19$ \\
\hline \multicolumn{7}{|c|}{ Water content (\%) } \\
\hline Non-diabetic & 14 & $64.41^{\mathrm{a}}$ & 0.36 & 13 & $62 \cdot 71^{\mathrm{a}}$ & 0.38 \\
\hline Diabetic & 12 & $68 \cdot 55^{a}$ & 0.55 & 14 & $69 \cdot 39^{\mathrm{a}}$ & 0.67 \\
\hline \multicolumn{7}{|c|}{ Glycaemia (mg/ml) } \\
\hline Non-diabetic & 14 & $1.440^{\mathrm{a}}$ & 0.080 & 13 & $1.030^{\mathrm{a}}$ & 0.030 \\
\hline Diabetic & 12 & $4 \cdot 370^{\mathrm{b}}$ & 0.345 & 14 & $4 \cdot 763^{\mathrm{b}}$ & 0.310 \\
\hline
\end{tabular}

${ }^{a, b}$ Mean values with unlike superscript letters were significantly different $(P<0.05)$.

* For details of procedures, see p. 510.

DM besides the decreased body weight $(P<0.05)$ noted in pups from diabetic mothers. Maternal DM led to a significant increase $(P<0 \cdot 05)$ in pups glycaemia.

\section{Discussion}

The current study demonstrated that DM led to an increase of the energy expenditure not only in non-pregnant, but also in pregnant animals. All of our diabetic animals were treated daily with insulin in order to avoid large differences in the individual glycaemia values among diabetic animals, as well as to keep the glycaemia levels into a range that allowed the animals survival.

The pregnancy, as expected, increased the energy expenditure as a consequence development of conceptuses and placentas (Rosso, 1975; Luz \& Griggio, 1990; Hay, 1991). In order to compensate for this increased energy expenditure, the animals enhanced their metabolizable energy intake and showed increase in the net bodyweight gain (Luz \& Griggio, 1992, 1998).

It has been found that type $1 \mathrm{DM}$ usually leads to an increase in energy expenditure in human subjects and animals (Nair et al. 1984; Molnár et al. 1989). This increase is attributed mainly to a higher protein catabolism (Bennet

Table 4. Weight and energy content of uteruses from non-pregnant and pregnant rats in different states (diabetic and non-diabetic)* (Mean values with their standard errors)

\begin{tabular}{|c|c|c|c|c|c|c|}
\hline \multirow[t]{2}{*}{ State... } & \multicolumn{3}{|c|}{ Non-pregnant } & \multicolumn{3}{|c|}{ Pregnant } \\
\hline & $n$ & Mean & SEM & $n$ & Mean & SEM \\
\hline \multicolumn{7}{|l|}{ Uterus weight (g) } \\
\hline Non-diabetic & 14 & $0.63^{a}$ & 0.03 & 13 & $3.75^{c}$ & 0.12 \\
\hline Diabetic & 12 & $0.55^{\mathrm{b}}$ & 0.04 & 14 & $3.50^{d}$ & 0.12 \\
\hline \multicolumn{7}{|c|}{ Uterus energy content (kJ) } \\
\hline Non-diabetic & 14 & $2 \cdot 81^{a}$ & 0.32 & 13 & $15 \cdot 76^{\mathrm{b}}$ & $1 \cdot 37$ \\
\hline Diabetic & 12 & $3 \cdot 16^{\mathrm{a}}$ & 0.24 & 14 & $14 \cdot 17^{\mathrm{b}}$ & 0.60 \\
\hline
\end{tabular}

$\overline{\mathrm{a}, \mathrm{b}, \mathrm{c}, \mathrm{d} M e a n}$ values with unlike superscript letters were significantly different $(P<0.05)$.

${ }^{*}$ For details of procedures, see p. 510. et al. 1991; Charlton \& Nair 1998a), besides hyperglucagonaemia (Salter, 1960; Boden et al. 1977; Nair et al. 1987) and higher thermogenic response to adrenaline (Shamoon et al. 1980; Müller et al. 1989). Our present results, in agreement with this literature, showed an increased energy expenditure in diabetic animals in both pregnant and non-pregnant (about 16 and $23 \%$ respectively) compared with the respective non-diabetic animals. In order to compensate for the increased energy expenditure, diabetic animals enhanced their metabolizable energy intake. Besides the hyperphagia, pregnant diabetic animals were not able to maintain the body-weight and body-energy gain at the same levels shown by control animals which can be explained by the lower gross food efficiency presented by them. Impairment of gross food efficiency is probably due to higher costs of protein synthesis (Nair et al. 1984) and gluconeogenesis (Nair et al. 1984) present in diabetic subjects. It is interesting to notice that DM even led to an inhibition of the characteristic increase of gross food efficiency during pregnancy as previously reported (Luz \& Griggio, 1990). DM can lead to gastrointestinal alterations such as dysphagia, abdominal pain, nausea,

Table 5. Urine volume and energy content from non-pregnant and pregnant rats in different states (diabetic and non-diabetic)* (Mean values with their standard errors)

\begin{tabular}{|c|c|c|c|c|c|c|}
\hline \multirow[t]{2}{*}{ State... } & \multicolumn{3}{|c|}{ Non-pregnant } & \multicolumn{3}{|c|}{ Pregnant } \\
\hline & $n$ & Mean & SEM & $n$ & Mean & $\mathrm{SE}$ \\
\hline \multicolumn{7}{|c|}{ Urinary volume $(\mathrm{ml} / \mathrm{d}) \dagger$} \\
\hline Non-diabetic & 14 & $8 \cdot 68^{a}$ & 0.37 & 13 & $11 \cdot 88^{\mathrm{a}}$ & \\
\hline Diabetic & 12 & $56 \cdot 23^{b}$ & 6.66 & 14 & $64 \cdot 00^{\mathrm{b}}$ & \\
\hline \multicolumn{7}{|c|}{ Urinary energy $(\mathrm{kJ} / \mathrm{g}) \ddagger$} \\
\hline Non-diabetic & 14 & $5 \cdot 91^{\mathrm{a}}$ & 1.02 & 13 & $6 \cdot 88^{\mathrm{C}}$ & \\
\hline Diabetic & 12 & $21 \cdot 62^{b}$ & 3.89 & 14 & $18 \cdot 21^{\mathrm{bd}}$ & \\
\hline
\end{tabular}

a,b,c,dMean values with unlike superscript letters were significantly different $(P<0.05)$.

${ }^{*}$ For details of diets and procedures, see p. 510.

†Daily urinary volume was averaged over the $21 \mathrm{~d}$ of the experiment.

¥Urinary energy was obtained from a sample of the urine collected over $21 \mathrm{~d}$ of the experiment. 
Table 6. Plasma glucose $(\mathrm{mg} / \mathrm{ml})$ and variables at birth of offspring from nonpregnant and pregnant rats in different states (diabetic and non-diabetic) †‡

(Mean values with their standard errors)

\begin{tabular}{|c|c|c|c|c|}
\hline \multirow[t]{2}{*}{ State... } & \multicolumn{2}{|c|}{ Non-diabetic ( $n$ 13) } & \multicolumn{2}{|c|}{ Diabetic ( $n$ 14) } \\
\hline & Mean & SEM & Mean & SEM \\
\hline Pups $(n)$ & $11 \cdot 1$ & 0.7 & $10 \cdot 6$ & 0.6 \\
\hline \multicolumn{5}{|l|}{ Weight (g) } \\
\hline Pups & 4.92 & 0.19 & $4 \cdot 00^{*}$ & 0.26 \\
\hline Placentas & 0.65 & 0.02 & 0.70 & 0.05 \\
\hline \multicolumn{5}{|l|}{ Energy (kJ) } \\
\hline Pups & $12 \cdot 53$ & 0.59 & $10 \cdot 65$ & 1.04 \\
\hline Placentas & $2 \cdot 00$ & 0.06 & $2 \cdot 16$ & 0.13 \\
\hline Glycaemia of pups (mg/ml) & 1.090 & 0.130 & $3 \cdot 852^{*}$ & 0.291 \\
\hline
\end{tabular}

Mean values were significantly different from those of the non-diabetic group: ${ }^{*} P<0 \cdot 05$.

†For details of diets and procedures, see p. 510.

‡ Each individual body weight, body energy value and glycaemia value corresponded to the average of the pooled body weight and energy value of the offspring from each dam.

vomiting, diarrhoea and malabsorption. These symptoms can be associated with altered gastrointestinal muscarinic response (Altan et al. 1987) and functional alterations in gastrointestinal gap junctions, which could result in a decreased gastrointestinal motility (Öztürk et al. 1997), and reduction in nutrient absorption. Nevertheless, our diabetic animals did not show any alterations of their absorptive capacity represented in the present study as the percentage of absorbed energy.

Insulin deficiency is usually accompanied by elevation of plasma fatty free acid concentration as a result of increased free fatty acid outflow from fat depots, where the balance of the free fatty acid esterification-tryacylglycerol lipolysis cycle is displaced in favour of lipolysis (Felig \& Bergman, 1995). Thus, as expected, our diabetic animals, pregnant or not, showed a significant reduction in their carcass fat content.

Besides fat metabolism alterations, diabetic subjects can show a negative $\mathrm{N}$ balance and marked substrate wasting which is not surprising, since insulin, when present in normal amounts, stimulates protein synthesis and amino acid uptake and inhibits protein catabolism and the output of amino acids from muscle (Felig \& Bergman, 1995). In fact, we did not detect significant differences between carcass protein content for pregnant diabetic animals, probably because of insulin administration, but non-pregnant diabetic rats had an increased protein content in the carcass.

Considering that pregnancy leads to uterus hypertrophy, an increase in the weight and energy content in this tissue is expected during this period (Luz \& Griggio, 1998). On the other hand, a reduction in uterus weight could be expected in diabetic animals since DM can alter the hypothalamus-hypophysis-ovary axis leading to a reduction in plasma concentrations of the luteinizing hormone, folliclestimulating hormone, prolactin and oestrogen (La Marca et al. 1999), and it is reported that a decrease in oestrogen levels can reduce uterus size (Merry \& Holehan, 1994). Accordingly, we observed a reduction in uterus weight in diabetic animals.

It is widely known that polyuria, glucosuria and proteinuria occur in diabetic subjects (Felig \& Bergman, 1995).
Therefore, the results obtained for urinary variables were expected, since the glucose and protein content present in urine from diabetic animals must raise their urinary energy losses. The urinary energy losses represented $2 \cdot 3$ and $21.3 \%$ absorbed energy for control and diabetic animals respectively, while pregnancy did not affect these variables.

The effects of DM on the development of fetuses and placentas are controversial. A high incidence of congenital malformation (Diamant, 1991; Giavini et al. 1993; Menegola et al. 1995; Siman \& Ericksson, 1997), abortion, and fetal reabsorption (Giavini et al. 1993; Siman \& Ericksson, 1997) have been reported during diabetic pregnancies. Some authors have reported increased fetal and placental weights (Hod et al. 1991; Mayhew et al. 1993; Boden, 1996; Fu et al. 1996) from diabetic mothers while others have reported decreased (Atkins et al. 1994; Takenaka \& Toyoda, 1995; Claubat et al. 1997) or no alteration (Ezekwe et al. 1984; Clarson et al. 1989) in weight. Our present results show that the maternal DM affected only the fetuses' weight, whereas there were no differences in the number of fetuses and placentas or their energy content nor in placental weight.

It is known that fetal glycaemic status tracks that of the mother, with fetal hyperglycaemia and hyperinsulinaemia subsequent to maternal hyperglycaemia (Illisley, 2000) and, considering the fetuses' capacity for insulin release, it is expected that glycaemia would be lower in fetuses than their mothers (Rudge et al. 1995). In accordance with Uvena-Celebrezze \& Catalano (2000), fetal blood glucose levels in utero are approximately $70-80 \%$ of maternal glucose levels. Consistent with these previous observations, we found that fetuses showed had glycaemia levels lower than those of their mothers $(80.9 \%)$.

The present study shows that DM impaired energy deposition in pregnant animals due to high energy expenditure. Furthermore, in pregnant animals, DM blocked the improvement in food efficiency and fat deposition usually seen during pregnancy, leading to a loss of weight or energy of the dams and the offspring, which were born with lower body weight than controls.

Several of the DM-related impairments described are 
also shown in human subjects, which suggests that the rat is a good experimental model for DM. Differences described may be related to insulin therapy imposed on human subjects, which is quite different from the present experimental procedure. Insulin was given to rats to keep glycaemia at equally high levels among the group and to avoid interruption of gestation that otherwise would occur, rather than as a therapeutic procedure to control it.

\section{Acknowledgements}

This work was supported by grants from FAPESP and CNPq.

\section{References}

Altan VM, Yildizoglu N \& Öztürk Y (1987) Decreased gastrointestinal response to certain agonists in streptozotocin-and alloxan-diabetic rats in vitro. Pharmacology 34, 143-149.

Anderson S, Jung FF \& Ingelfinger JR (1993) Renal renin-angiotensin system in diabetes: functional, immunohistochemical, and molecular biological correlations. American Physiology Society 34, F477-F486.

Andrews JF, Richard D, Jennings G \& Trayhurn P (1986) Brown adipose tissue thermogenesis during pregnancy in mice. Annals of Nutrition and Metabolism 30, 87-93.

Atkins V, Flozak AS, Ogata ES \& Simmons RA (1994) The effects of severe maternal diabetes on glucose transport in fetal rat. Endocrinology 135, 409-415.

Bennet WM, Connacher AA, Jung RT, Stehle P \& Rennie MJ (1991) Effects of insulin and aminoacids on leg protein turnover in IDDM patients. Diabetes 40, 499-508.

Boden G (1996) Fuel metabolism in pregnancy and in gestational diabetes mellitus. Obstetric and Gynecology Clinics of North America 23, 1-10.

Boden G, Owen OE, Rezvani I, Ecfenlecin IB \& Ovickel KE (1977) An islet cell carcinoma containing glucagon and insulin. Chronic glucagon excess and glucose homeostasis. Diabetes 26, $128-137$.

Charlton M \& Nair KS (1998a) Protein metabolism in insulindependent diabetes mellitus. Journal of Nutrition 128, 323S-327S.

Charlton M \& Nair KS (1998b) Role of hyperglucagonemia in catabolism associated with type 1 diabetes - effects on leucine metabolism and the resting metabolic rate. Diabetes $\mathbf{4 7}$, $1748-1756$.

Chaves JM \& Herrera E (1980) In vitro response of glycerol metabolism to insulin and adrenaline in adipose tissue from fed and fasted rats during pregnancy. Biology of the Neonate 38, 139-145.

Clarson C, Tevaarwerk GJ, Harding PG, Chance GW \& Haust MD (1989) Placental weight in diabetic pregnancies. Placentae 10, 275-281.

Claubat M, Stirnemann B, Bouftila B \& Robert I (1997) Beneficial effect induced by a beta-adrenoceptor blocker on fetal growth in streptozotocin-diabetic rats. Biology of Neonate $\mathbf{7 1}$, $171-180$.

Diamant YZ (1991) The placenta in diabetes mellitus. Israel Journal of Medical Science 27, 493-497.

Ezekwe MO, Ezekwe EI, Sem DK \& Ogolla F (1984) Effects of maternal streptozotocin-diabetes on fetal growth, energy reserves and body composition of newborn pigs. Journal of Animal Science 59, 974-980.

Felig P \& Bergman M (1995) The endocrine pancreas: diabetes mellitus. In Endocrinology and Metabolism, pp. 1107-1250
[P Felig, JD Baxter and LA Frohman, editors]. New York, NY: McGraw-Hill Inc.

Folch J, Lees M \& Sloane-Stanley GHA (1957) A simple method for isolation and purification of total lipides from animal tissue. Journal of Biological Chemistry 226, 497-509.

Forsum E, Sadurskis A \& Wager J (1988) Resting metabolic rate and body composition on healthy Swedish women during pregnancy. American Journal of Clinical Nutrition 47, 942-947.

Fu Q, Honda M, Ohgawara H, Igarashi N, Toyoda C, Omori Y \& Kobayashi M (1996) Morphological analysis of pancreatic endocrine cells in newborn animals delivered by experimental diabetic rats. Diabetes Research and Clinical Practice 32, 57-62.

Geiger H, Bahner U, Vaaben W, Dammrich J, Heidland A \& Luft FC (1992) Effects of angiotensin-converting enzyme inhibition in diabetic rats with reduced renal function. Journal of Laboratory and Clinical Medicine 6, 861-868.

Giavini E, Airoldi L, Broccia ML, Roversi GD \& Prati M (1993) Effects of diets with different content in protein and fiber on embryotoxicity induced by experimental diabetes in rats. Biology of the Neonate 63, 353-359.

Grishan FK (1993) Calcium transport by basolateral membranes of diabetic rats. American Journal of Clinical Nutrition 58, 209-214.

Hay WW Jr (1991) Energy and substrate requirements of the placenta and fetus. Proceedings of Nutrition Society 50, 321-366.

Hirsch RP \& Riegelman RK (1992) Statistical First Aid: Interpretation of Health Research Data. Boston, MA: Blackwell Scientific Publications.

Hod M, Merlob P, Friedman S, Rusecki Y, Schoenfeld A \& Ovadia J (1991) Prevalence of congenital anomalies and neonatal complications in the offspring of diabetic mothers in Israel. Israel Journal of Medical Science 27, 498-502.

Illisley NP (2000) Placental glucose transport in diabetic pregnancy. Clinical Obstetrics and Gynecology 43, 116-126.

La Marca A, Morgante G \& De Leo V (1999) Evaluation of hypothalamic-pituitary-adrenal axis in amenorrhoeic women with insulin-dependent diabetes. Human Reproduction 14, 298-302.

Leshner AI \& Litwin VA (1972) A simple method for carcass analysis. Physiology and Behavior 9, 282-289.

Luz J \& Griggio MA (1990) Energy balance of pregnant rats. Brazilian Journal of Medical and Biological Research 23, 729-733.

Luz J \& Griggio MA (1992) Energy balance of pregnant rats in a cold environment. Journal of Thermal Biology 17, 235-239.

Luz J \& Griggio MA (1998) Effects of aging on the energy balance of pregnant rats. Annals of Nutrition and Metabolism 42 , 237-243.

Mayhew TM, Sorensen FB, Klebe JG \& Jackson MR (1993) The effects of mode of delivery and sex of newborn on placental morphology in control and diabetic pregnancies. Journal of Anatomy 183, 545-552.

Menegola E, Prati M, Broccia ML, Ricolfi R \& Giavini E (1995) In vitro development of rat embryos obtained from diabetic mothers. Experientia 51, 394-397.

Merry BJ \& Holehan AM (1994) Aging of the female reproductive system: the menopause. In Physiological Basis of Aging and Geriatrics, pp. 147-170 [PS Timiras, editor]. Boca Raton, FL: CRC Press.

Molnár D, Decsi T \& Soltesz G (1989) Increased thermogenesis in children with type I diabetes. British Medical Journal 299 , 919.

Müller MJ, Mühlen A, Lautz HU, Schmidt FW, Daiber M \& Hurter P (1989) Energy expenditure in children with type I diabetes: evidence for increased thermogenesis. British Medical Journal 299, 487-491.

Murphy SP \& Abrams BF (1993) Changes in energy intake 
during pregnancy and lactation in a national sample of US women. American Journal of Public Health 83, 1161-1163.

Nair KS, Halliday D \& Garrow JS (1984) Increased energy expenditure in poorly controlled type 1 (insulin-dependent) diabetic patients. Diabetologia 27, 13-16.

Nair KS, Halliday D, Matthews DL \& Welle SL (1987) Hyperglucagonemia during insulin deficiency accelerates protein catabolism. American Journal of Physiology 253, E208-E213.

Nair KS (1987) Hyperglucagonemia increases resting metabolic rate in man during insulin deficiency. Journal of Clinical Endocrinology and Metabolism 64, 896-901.

Naismith DJ \& Brookes RH (1983) Energetic efficiency during pregnancy. Proceedings of Nutrition Society 64, 79A.

Öztürk Y, Aydin S, Özçelikay AT, Altan VM \& Yildizoglu-Ari N (1997) Calmodulin content and in vitro contractility of duodenum from streptozotocin-induced diabetic rats: effects of insulin therapy and calmodulin antagonism. European Journal of Pharmacology 321, 59-65.

Richard D \& Trayhurn P (1985) Energetic efficiency during pregnancy in mice fed ad libitum or pair-fed to the normal energy intake of unmated animals. Journal of Nutrition 115, 593-600.

Rosso P (1975) Changes in the transfer of nutrients across placenta during normal gestation in the rat. American Journal of Obstetrics and Gynecology 122, 761-766.

Rudge MVC, Calderon IMP, Ramos MD \& Rodriguez MAM
(1995) Diabetes and experimental pregnancy in rats: course of maternal blood glucose levels and its repercussions on the blood glucose levels and pancreas of newborn pups. Brazilian Journal of Medical and Biological Research 28, 219-255.

Salter JM (1960) Metabolic effects of glucagon in the Wistar rat. American Journal of Clinical Nutrition 8, 535-539.

Shamoon H, Hendler R \& Sherwin RS (1980) Altered responsiveness to cortisol, epinerine, and glucagon insulin-infused juvenile onset diabetics. Diabetes 29, 284-291.

Siman CM \& Ericksson UJ (1997) Vitamin E decreases the occurrence of malformations in the offspring of diabetic rats. Diabetes 46, 1054-1061.

Takenaka Y \& Toyoda N (1995) The effect of alpha 1-blocking vasodilator on fetal growth and uteroplacental blood flow in streptozotocin-induced diabetic rats. Life Science 56, 1127-1134.

Trayhurn P (1989) Thermogenesis and the energetics of pregnancy and lactation. Canadian Journal of Physiology and Pharmacology 67, 370-375.

Uvena-Celebrezze J \& Catalano PM (2000) The infant of the woman with gestational diabetes mellitus. Clinical Obstetrics and Gynecology 43, 127-139.

Wongsurawat N \& Armbrecht HJ (1991) Calcitonin stimulates 1,25-dihydroxyvitamin $\mathrm{D}$ production in diabetic rat kidney. Metabolism 40, 22-25. 